\title{
Human Capital Management and Industry 4.0
}

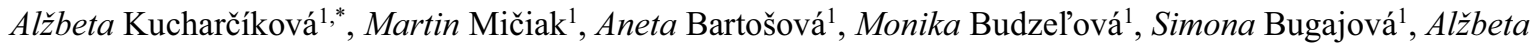 \\ Maslíková ${ }^{1}$, Simona Pisoňová ${ }^{1}$ \\ ${ }^{1}$ Department of Macro and Microeconomics, Faculty of Management Science and Informatics, University of Žilina, Univerzitná \\ 8215/1, 010 26, Žilina, Slovak Republic
}

\begin{abstract}
Human capital (HC) is considered to be an important factor influencing the success of. The concept of human capital management (HCM) deals with the effectiveness of human capital, as the most precious intangible asset. However, with the advancement in technology and the introduction of Industry 4.0 , the position of human capital in companies can alter with regard to the expected changes. On the other hand, new elements being brought in by Industry 4.0 will allow for the HCM process to be performed better, in favour of the improvement in the performance and competitiveness of companies. The aim of this article is to point out the interconnection between the concept of HCM and some elements of Industry 4.0, as well as to explain the findings from a questionnaire survey focused on how IT companies in Slovakia use information systems for the implementation of HCM, whether these systems enable them to analyse data related to $\mathrm{HC}$, and whether these companies are prepared for the introduction of changes in this field in the future.
\end{abstract}

Keywords: human capital management; Industry 4.0; information systems; digitization; big data

\section{Introduction}

Employees are currently considered to be the most valuable asset of an organization [1]. Human capital (HC) is one of production inputs of companies. The increase in the human capital value is an important way to increase a company's market value. Highly qualified HC ensures the strong competitiveness of companies. By investing in HC, a company increases the knowledge, skills and abilities of its employees, who can make the production of the company more efficient and generate profit.

Human capital is a constituent of intellectual capital, which represents the key, long-term knowledge of a company in the competitive environment. These pieces of knowledge are used in the strategic management of a company while being created as a combination of pieces of information and knowledge from the company's external surroundings [2]. Similarly to other production inputs, HC also needs to be managed, and with the intention of strengthening the competitiveness, new ways in which its effectiveness can be enhanced need to be sought after. This is what human capital management (HCM) is focused on.

\subsection{Human Capital Management}

HCM represents an approach to personnel management. The correct estimation of talent [3], motivation and the placement of the right people in the right positions can optimize the utilization of human resources. According to Lawler [4], the purpose of HCM lies in the retention of capable employees in a company, whose activity is reflected in the overall operations of the company. For companies, it is of vital importance to implement a policy for motivating employees at the right time, which helps achieve competitive advantage. Ghosh [5] understands the substance of HCM to be an overarching concept, including a set of practices, organizational needs, technologies and abilities with the aim of obtaining organizational capability for the acquisition, management and optimization of the workforce. HCM can also be defined as the management of employees in a company that ensures that each employee contributes to overall productivity through their skills and knowledge [6].

The Gartner company defines HCM as a set of procedures needed for the acquisition, management and optimization of the workforce within human resources management. The application of methods and procedures within the HC field can be performed in any organization, but it is especially suitable for those organizations where people play the most important role [7]. The Personio company [8] defines the main principle of successful HCM as the placement of the right person in a company in the right position at the right time. The consideration of talent and the personality of the individual, accompanied by their training and professional development, can help create a perfect candidate for a job vacancy.

\footnotetext{
${ }^{*}$ Corresponding author: alzbeta.kucharcikova@fri.uniza.sk
} 
HCM is a modern concept of people management that is considered to be a supplement to human resources management. HCM represents a process consisting of seven phases, which is inevitably connected to a company's strategy. The basic elements of HCM are represented by key performance indicators [9-11], metrics for the expression of $\mathrm{HC}$ value, metrics for the effectiveness of $\mathrm{HC}$ utilization, and metrics for the effectiveness of investments in HC. Except for these elements, HCM is also a complex of corrective measures and reports on HC [12]. The HCM process is affected by many external as well as internal factors. The external factors include the situation in the labour market, economic policy measures [13], a company's suppliers, customers and competitors, as well as the technological advances and innovation environment in a country. The internal factors are represented, for example by the remuneration system, motivation program [14-16], corporate culture [17], employee turnover, and so on.

\subsection{Industry 4.0 and the management of people}

Another external factor influencing HCM is represented by the ongoing processes related to Industry 4.0 which is helping to develop and improve the third industrial revolution through intelligent and automated systems based on big data and machine learning [18]. Industry 4.0 and its implementation are closely related to technologies such as the Internet of Things, information and communication systems, business architecture, and so on [19]. It is estimated that Industry 4.0 and the gradual digitization of manufacturing will greatly affect human resources and their position in companies. Technological advances will change the structure of the workforce in a short period of time and will partially cause unemployment [20]. From a long-term perspective, the quality of the workforce will increase, alongside the level and quality of education [21]. Therefore, it can be presumed that, over time, the people employed in companies will be highly qualified individuals [22].

The fusion of human resources and human capital under Industry 4.0 has been the subject of several research studies. The main findings imply that Industry 4.0 would lead to a considerable decrease in standardized work tasks with low qualification needs, and to an increase in the tasks that require a high level of qualification. This is connected to the increase in demand for workers that can take care of planning, checking and the associated IT related tasks. According to Bonekamp and Sure [23], the majority of researchers expect an increase in the complexity of many job profiles as well as an increase in the continuous learning, professional training and development of employees so that they are able to adapt to new requirements.

It is also assumed that the transformation of industry, in connection with the business environment, will have an impact on the processes of human resources and human capital management. While technologically integrated business processes can cause the loss of employment for some low-qualified employees, the need for a highly qualified workforce will rise. However, there may be an issue with finding the highly qualified workforce required and with the subsequent complications of retaining these highly qualified employees [22].

Industry 4.0 requires human capital to be supported by continuous learning and the utilization of education systems that are more focused on knowledge beyond what is currently needed. It is not only about education in companies. According to Agolla [24] the effective integration of Industry 4.0 requires learning and development of HC from early childhood. The determinative role is not only played by higher education, but also by the right preschool, elementary, secondary or vocational education.

The implementation of HCM in an organization can change the overall approach to its management. Setting appropriate frameworks and technological systems can help with the acquisition of suitable talents and their right integration and retention [25]. For companies to be competitive today, it is not sufficient to just implement progressive methods in the management of people. These methods also need to be connected to the elements of the Industry 4.0 process, modern information systems (IS), digitization, the Internet of Things, advanced data analytics and so on. Only when the technologies, technological advances and innovations get gradually transformed from external factors into internal ones, can companies effectively use them in favour of their overall effectiveness and future competitiveness.

\section{Methodology}

Industry 4.0 gives companies a lot of different tools with which to increase the effectiveness of their processes. This also concerns the field of HCM. However, it is still questionable whether companies use at least some of the elements of Industry 4.0 and whether they are willing to consider changes in the future. The aim of this article is to point out the interconnections between the concept of HCM and elements of Industry 4.0 and to explain some of the findings from a questionnaire survey focused on whether IT companies in Slovakia use ISs for the implementation of HCM concept, whether these ISs enable them to analyse data related to $\mathrm{HC}$, and whether the companies are prepared for the introduction of further changes in this field.

The article presents the application of several scientific methods. These include the analysis, comparison and systemization of pieces of knowledge within the field of human capital management, Industry 4.0 and the accompanying phenomena. In the next step, the results of an original extensive questionnaire survey are used. This survey was conducted in 2018 and the responses from 113 IT companies operating in Slovakia were collected. The attention was directed towards IT companies due to their presence in a knowledge-intensive industry of the economy. It can also be assumed 
that these companies will represent an example for others in relation to the introduction of new concepts for the management of people in connection with elements of Industry 4.0. For this article, the answers to three selected questions from the survey were processed and thoroughly analysed.

\section{Results}

\subsection{Use of ISs in companies for human resources and HCM}

This part of the questionnaire was focused on the current state of the possible informational support for the implementation of the concept of HCM. The respondents (HR managers of IT companies) were asked to disclose what IS they used in the company for the field of human resources or directly for HCM if they had already partially implemented the concept. The IS being used helps to identify what types of data are being collected, and with the use of what other technologies other types of data could be collected, processed and used while measuring and assessing the effectiveness of HC.

The question in the survey was open so that respondents were not limited by a predefined scale. Subsequently, the responses could be put into common categories, based on their frequencies. For the processing and evaluation within this question, only 70 usable responses were collected. The statistical description of the set of companies from which the responses were collected is presented in Table 1.

Table 1. Structure of the sample of companies

\begin{tabular}{|c|c|c|c|c|c|}
\hline Company size & $\begin{array}{c}\text { Number } \\
\text { companies }\end{array}$ & $\%$ & $\begin{array}{c}\text { Majority } \\
\text { owner }\end{array}$ & Number of companies & $\%$ \\
\hline micro-company & 25 & 35.71 & domestic & 50 & 71 \\
\hline small company & 15 & 21.43 & \multirow[b]{3}{*}{ foreign } & \multirow[b]{3}{*}{20} & \multirow[b]{3}{*}{29} \\
\hline medium-sized company & 15 & 21.43 & & & \\
\hline large company & 15 & 21.43 & & & \\
\hline Total & 70 & 100 & Total & 70 & 100 \\
\hline
\end{tabular}

Source: Authors.

The aggregate results include only those ISs that were stated at least by two respondents. Other ISs, stated only by a single respondent, were put into the category "other IS". The results processed in this way are depicted in Figure 1.

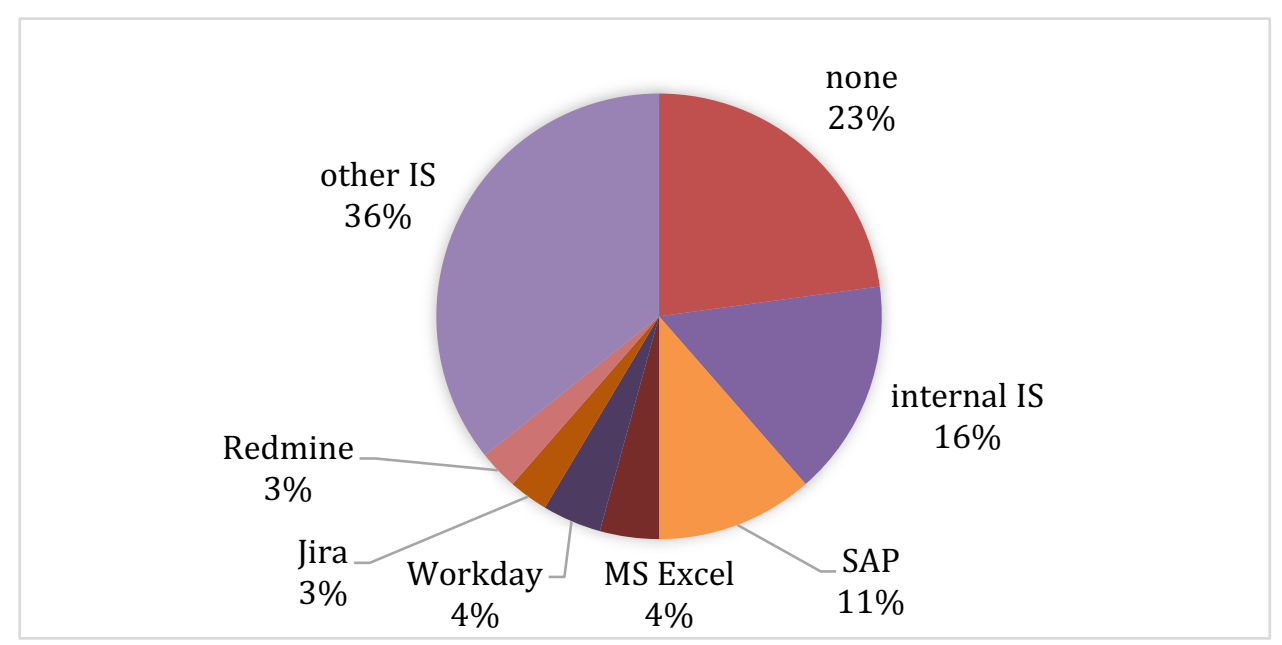

Figure 1. ISs used in the companies for $\mathrm{HR}$ and $\mathrm{HC}$

Source: Authors.

The greatest portion of responses was represented by other IS (36\%), followed by no specific IS (23\%). The latter may be caused by the greater proportion of micro-companies within the sample. The third most popular response was the use of internal ISs developed and adjusted according to the company's needs (16\%).

The IS SAP within the given field is used mainly by large companies (more than $33 \%$ of such companies) and by companies with foreign majority owners (30\% of such companies). On the other hand, among the companies where the respondents stated that they did not use any IS for the field of HR or HC, there were mainly micro-companies (52\% of such companies) and companies with domestic majority owners (32\% of such companies). 
The results therefore revealed the use of a spectrum of ISs, ranging from spreadsheets for the creation and organization of the related records to sophisticated systems whose adjustment and extension is usually complicated and costly. The ISs identified by the respondents can be the object of further analysis for the evaluation of possibilities within the implementation of the concept of HCM and elements of Industry 4.0. The key issue here is to make sure that the implemented IS is suitable for the given. Company and that its application facilitates and supports the practical usage of the concept.

\subsection{Support for the monitoring and analysis of data related to HC in the IS used}

Another question in the survey was focused on the identification and description of how the IS used enables the HR managers to monitor and process the data related to $\mathrm{HC}$.

This question was answered by 95 respondents. Therefore, the sample size for this question was bigger, while the structure of the sample in relation to company size and majority ownership remained comparable. The greater number of respondents means that the responses were given also by the managers who did not state a concrete name of the IS used in the previous question. Thus, the ISs used by them can be the same to those collected, but there can also be other specific software products. For this reason, the additional analysis of the information support for HCM can also be focused on other software products. This can be done using the information on websites of IS providers or the experience of users of these ISs captured in case studies.

The closed question focused on the perceived support for the monitoring and analysis of data related to HC. Respondents could choose from: the IS used allowed them to fully monitor and evaluate HC data based on all the metrics and indicators they use; the system allowed them only to monitor the qualifications of the employees and the completed learning and development activities; the system did not provide any monitoring of HC at all. The results captured in the form of relative frequencies are presented in Figure 2.

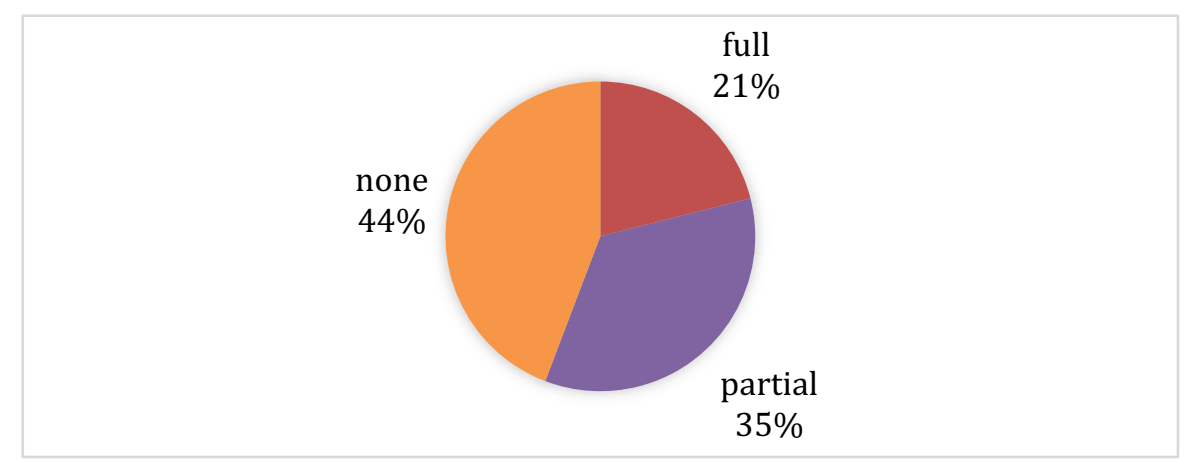

Figure 2. Informational support for the monitoring and analysis of $\mathrm{HC}$ data

Source: Authors.

The results show that the informational support for the concept of HCM is still relatively low, with only $20 \%$ of companies stating that their IS provided full support for all the metrics and indicators for HC. In contrast, up to $44 \%$ of companies stated that the IS they used did not allow them to monitor the metrics and indicators needed for the management of $\mathrm{HC}$ at all. This needs to be put into relation with the results from the previous question where many respondents, mainly from smaller companies, stated that they did not use any IS for the field of HR and HC. To confirm such a tendency with regards to the perceived informational support for HCM in the ISs, the results were further statistically analysed.

In relation to company size, statistically significant differences were detected, as supported by the following test results: $\chi^{2}(6)=32.379$; at the critical value of $\mathrm{C}=12,592$; $\mathrm{p}$-value $<0.001$; significance level of $\alpha=0.05$. These statistical test results are reflected in terms of absolute and relative frequencies according to company size in Table 2.

Table 2. Differences in informational support for $\mathrm{HC}$ according to company size

\begin{tabular}{|l|c|c|c|c|c|c|c|c|}
\hline $\begin{array}{l}\text { HC } \\
\text { support } \\
\text { in the IS }\end{array}$ & $\begin{array}{c}\text { Micro- } \\
\text { company }\end{array}$ & $\begin{array}{c}\text { \% } \\
\text { within } \\
\text { the } \\
\text { group }\end{array}$ & $\begin{array}{c}\text { Small } \\
\text { company }\end{array}$ & $\begin{array}{c}\text { \% } \\
\text { within } \\
\text { the } \\
\text { group }\end{array}$ & $\begin{array}{c}\text { Medium- } \\
\text { sized } \\
\text { company }\end{array}$ & $\begin{array}{c}\text { \% } \\
\text { within } \\
\text { the } \\
\text { group }\end{array}$ & $\begin{array}{c}\text { Large } \\
\text { company }\end{array}$ & $\begin{array}{c}\% \\
\text { within } \\
\text { the } \\
\text { group }\end{array}$ \\
\hline Full & 2 & 5.00 & 5 & 25.00 & 4 & 22.22 & 9 & 52.94 \\
\hline Partial & 9 & 22.50 & 7 & 35.00 & 10 & 55.56 & 7 & 41.18 \\
\hline None & 29 & 72.50 & 8 & 40.00 & 4 & 22.22 & 1 & 5.88 \\
\hline
\end{tabular}

Source: Authors. 
This means that with regards to the perceived informational support for HCM in the IS used, again, higher values of partial or full informational support were recorded for larger companies.

This is followed by the statistical testing of the differences based on majority ownership. The identification of statistically significant changes is supported by the following test results: $\chi^{2}(2)=14.585$; at the critical value of $C=5,991$; $\mathrm{p}$-value $<0.001$; significance level $\alpha=0.05$. The reflection of the results in terms of absolute and relative frequencies can be seen in Table. 3. Overall, higher perceived support for HCM is present in companies with foreign majority owners.

Table 3. Differences in informational support for HC according to majority ownership

\begin{tabular}{|l|c|c|c|c|}
\hline $\begin{array}{l}\text { HC support in } \\
\text { the IS }\end{array}$ & $\begin{array}{c}\text { Domestic } \\
\text { owner }\end{array}$ & $\begin{array}{c}\text { \% within the } \\
\text { group }\end{array}$ & $\begin{array}{c}\text { Foreign } \\
\text { owner }\end{array}$ & $\begin{array}{c}\text { \% within } \\
\text { the group }\end{array}$ \\
\hline Full & 10 & $13.89 \%$ & 10 & $43.48 \%$ \\
\hline Partial & 23 & $31.94 \%$ & 10 & $43.48 \%$ \\
\hline None & 39 & $54.17 \%$ & 3 & $13.04 \%$ \\
\hline
\end{tabular}

Source: Authors.

\subsection{Expected introduction of changes leading to increased $\mathrm{HC}$ effectiveness}

The purpose of the question in relation to the above was to reveal whether the companies planned to introduce changes, including the application of ISs and enhanced, modern data processing, to increase the HC effectiveness.

This question was answered by 108 respondents (again, with comparable structure in relation to company size and majority ownership). The aggregate results expressed in terms of absolute frequencies are presented in Figure 3.

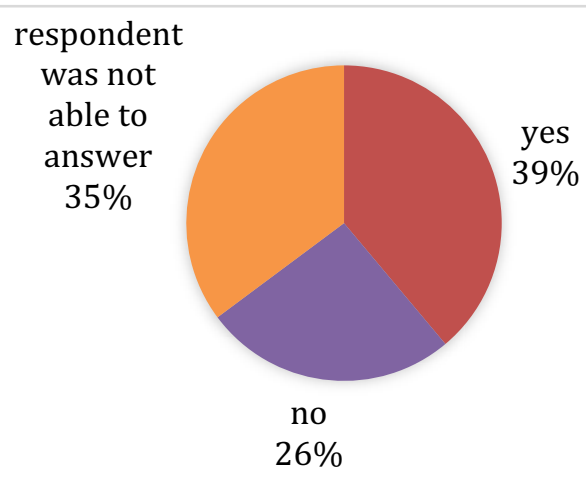

Figure 3. Expected changes leading to increased HC effectiveness

Source: Authors.

The results show a dominance of positive answers. This outcome supports further research in this field focused on the creation of practically applicable solutions the use of which will make it possible to precisely evaluate the effectiveness of $\mathrm{HC}$ utilization its changes over time and in relation to the measures taken as well as the business outputs and the introduction of elements of Industry 4.0.

When applying the statistical analysis, only statistically significant differences based on company size were detected. These are supported by the test results: $\chi^{2}(6)=20.221$; at the critical value of $\mathrm{C}=12.592$; $\mathrm{p}$-value $=0.003$; significance level $\alpha=0.05$. The structure of respondents' answers according to company size categories is presented in Table 4 .

Table 4. Differences in expected changes regarding increased HC effectiveness according to company size

\begin{tabular}{|l|c|c|c|c|c|c|c|c|}
\hline $\begin{array}{l}\text { Expected } \\
\text { changes }\end{array}$ & $\begin{array}{c}\text { Micro- } \\
\text { company }\end{array}$ & $\begin{array}{c}\text { within } \\
\text { the } \\
\text { group }\end{array}$ & $\begin{array}{c}\text { Small } \\
\text { company }\end{array}$ & $\begin{array}{c}\text { \%o } \\
\text { within } \\
\text { the } \\
\text { group }\end{array}$ & $\begin{array}{c}\text { Medium- } \\
\text { sized } \\
\text { company }\end{array}$ & $\begin{array}{c}\text { \%o } \\
\text { within } \\
\text { the } \\
\text { group }\end{array}$ & $\begin{array}{c}\text { Large } \\
\text { company } \\
\text { within } \\
\text { the } \\
\text { group }\end{array}$ \\
\hline Yes & 8 & 17.78 & 11 & 47.83 & 15 & 68.18 & 8 & 44.44 \\
\hline No & 19 & 42.22 & 4 & 17.39 & 2 & 9.09 & 3 & 16.67 \\
\hline $\begin{array}{l}\text { Respondent was } \\
\text { not able to answer }\end{array}$ & 18 & 40.00 & 8 & 34.78 & 5 & 22.73 & 7 & 38.89 \\
\hline
\end{tabular}

Source: Authors. 
Micro-companies did not expect changes to lead to the higher effectiveness of HC, whereas in the other company size categories such changes and measures were expected.

A deeper understanding of these findings was achieved via an analysis of reasons stated by the respondents. Of the respondents who expected the changes described, 25 of them also added reasons for this. These reasons support further research on the topic. They included a diverse combination of external and internal impacts. Among the reasons stated was the desire for continuous improvement, pressure from competitors, as well as recognition of the importance of HC and its effect on overall business results.

Of the respondents who did not expect changes in HC effectiveness due to IS and data analytics, 16 respondents stated reasons. These reasons included insufficient capacity or satisfaction with the current level of effectiveness. However, this creates a contradiction with the philosophy of continuous improvement, whereby such a managerial decision can lead to stagnation, which can be very dangerous for a company's existence in relation to Industry 4.0. Another reason stated was that the company was planning to focus on different priorities in the next period. Such a reason implies that HC is not a high priority in the company, which sends negative signals to current and potential employees and other stakeholders. A reason that can be perceived more positively was that effective utilization of $\mathrm{HC}$ was included as one of the long-term goals of a company. This means that in this company no sudden changes were expected in this field since it was being dealt with on a systematic basis. Finally, another respondent stated that such changes had already been implemented and that this can be positive as long as it concerns the appropriate implementation of the entire concept of HCM and not just isolated efforts, and the evaluation of the effects there of on the company's operation.

Finally, 5 respondents stated a reason for them not being able to provide an answer to the question on future changes leading to the increased HC effectiveness. Once again, managers stated they were satisfied with the current situation. This can be a consequence of neglecting to focus on continuous improvement in a field that is critically important for IT companies. Another reason stated was that the respondent had not seen sufficient and clear outcomes that can be achieved via the implementation of HCM. This is therefore a reflection of the need to study this field even deeper, in connection with business practice, and to edify the managers regarding the successful introduction of HCM and elements of Industry 4.0. It is only then that the interest of the managers in HCM can be increased so that its implementation can help them achieve better results related to performance, efficiency, competitiveness, and employee satisfaction.

\section{Discussion}

The survey among the IT companies has shown that within the implementation of HCM, these companies use a lot of different information systems ( $36 \%$ of companies using some other software product), $16 \%$ of them use their own internal systems, $11 \%$ use SAP. This system is mostly used by foreign companies. However, up to almost a quarter of companies do not use any IS in this field, while $52 \%$ of them are micro-companies.

The survey revealed that $20 \%$ of the companies had a system supporting the analysis of data related to HCM, but up to $44 \%$ of companies could not fully monitor, evaluate and report the data needed for modern HCM. This was recorded despite the fact that even greater emphasis is being put on the use of elements of Industry 4.0 such as digitization and Big Data analytics, in connection with HCM.

On the one hand, it is understandable that the companies might not have the necessary funds for this, but on the other hand, the benefits from digitization considerably surpass the investment needed. This transformation should be as accurate as possible, respecting the mutual relationships between the processes, objects, phenomena and so on. The information describing the events in the past that are being organized in the databases during digitization does not need to be laboriously sought after later when they are used, and they can be utilized as experience for future decisions on similar issues [26]. Due to the digitization of processes as a whole, the paper form of keeping records has been substituted by the digital one. Digitization enables the better classification and selection of data, as well as the application of various structures for using the data in a better way. For now, digitization is mostly being connected to manufacturing companies that are digitally transforming their whole production processes. In relation to people, this applies, for example to the digitization of employee performance records.

Microsoft Excel has become the most frequently used tool for management and planning. Within the original survey presented in this article, 4\% of IT companies are still using it instead of more complex and more expensive ISs. Even though this software was introduced more than 30 years ago, it is a successful tool for data processing in many small as well as larger companies. Its greatest advantage is its ease of use. A production worker with a paper version of a document is one of the most unstable elements in the process. Digitization eliminates the instability of the system, enables the realtime monitoring of the physical processes and can increase the reliability of the information. Via digital transformation, companies' can relieve themselves of a huge pile of papers, thereby creating a more interactive environment [27].

After different departments of companies including marketing, finance, sales or security, have undergone digitization, the challenge of digitization in the fields of $\mathrm{HC}$ and human resources becomes accepted [28]. The transition from paper to information systems and analytics allows companies to implement automation and support strategic growth and create a competitive advantage [29]. The willingness of companies to introduce changes can still be quite low at the moment. In the original survey, up to $40 \%$ of the companies did not express a willingness to implement changes related to HCM, the 
utilization of ISs and data analytics [30]. At first sight, it might seem that these companies would need to spend additional funds, time and other resources. However, the aim of digitization in the management of people is the automation of processes that are done repeatedly, so the time saved can be spent on strategic causes [31]. Instead of performing routine tasks, an employee can join the process of planning [32]. Kenny \& Company stated that with digitization, the data profiles of individual employees extended, which became one of the most important data sources within the organization. The information system then provides a wide range of data sets for the analysis, planning and decision-making in this field. The collected and aggregated data allows companies to identify trends related to the workforce together with the criteria for the job vacancies and the acquisition and retention of talents [29].

Industry 4.0 creates many challenges for companies with regards to the implementation of HCM as a modern concept of people management. Digitization, advanced analytics, Big Data and artificial intelligence have already begun changing the structure of work of HR specialists. Big Data are considered to be information assets, characterized by their large quantity, speed and variety, requiring specific technology and analytical methods for their transformation into value. Via Big Data analysis, a company can make better decisions [33], also in relation to the acquisition of the right talents for a certain job position.

Mauro et al. [34] deal with the use of Big Data in relation to people and their management. According to them, we live in a world where pieces of information are available everywhere. During the last few decades, exponential growth has been recorded in information flows, which has elicited the current integration. Pieces of information are now much more personal, in part because they are being directly consumed by the people using their personal devices. Technologies are becoming more and more accessible and more powerful when it comes to the processing of information. The efficiency of this processing is caused by fast calculations and accessibility of faster networks [35]. For the transformation of information into knowledge, it is necessary to use appropriate analytical methods and techniques. The latest analytical techniques used in the analysis of Big Data include cluster analysis [36], genetic algorithms, natural language processing, social network analysis, predictive models, data visualization, and others. Big Data analysis affects a wide range of fields including peoples' lives, culture and science. The effect can be positive as well as negative. According to Davenport, companies using Big Data can lower their costs, manage their processes more efficiently, and be more productive than their competitors. The negative impacts of Big Data analysis are related to the potential disruption of privacy and personal data [34].

Big Data analysis can be mostly utilized by companies with a larger number of employees because using these analytics enables them to find better solutions to problems connected with hiring, talent management, and so on. Via HR analytics, a company can cover up to nine fields in which it can increase its efficiency. These include the analysis of key employee skills, talent, workload, employee turnover, corporate culture, channel usage, leadership, as well as the individual and team performance of employees [37].

Big Data analysis is also related to the saving of the costs incurred by the employment of new people. If a company employs an unsuitable worker who leaves shortly after being hired, employee turnover rises, as do the overall personnel costs. If the companies use Big Data analysis before filling a job vacancy, they will be able to better predict who is suitable for the position and why, which will lower the turnover rate and the related costs. Besides that, Big Data analytics enables the monitoring of trends that can indicate how long the employee will stay in the company [38].

\section{Conclusion}

With the launch of the technologies related to Industry 4.0, companies become able to obtain and analyse more information than in the past. This amount rises every year due to modern software tools. For the field of human resources and $\mathrm{HC}$, this presents a challenge in the form of investment in efficient ISs for HCM, which is also related to Big Data analysis. Via this, some large international companies already can, and medium-sized and small companies will in the future be able to, improve their business operations $[39,40]$. For example, they can increase their employee retention rate and decrease the costs incurred as a result of employee turnover via better profiling of the requirements for a job position. The hiring of talents will be improved as well because the combination of Big Data analysis and an appropriate IS will improve the company's decision-making on hiring and the filtering of suitable candidates based on the keywords for a given position. Big Data analysis can also serve for the monitoring of work performance and the interaction between the best-performing employees and teams. The data can also serve to determine the optimal productivity of employees. Employee analytics will help companies analyse gaps in knowledge, directing the selection of the right training programs for the knowledge and skills that need to be developed. Logistic regression and predictive models will help with the estimation of the probability of the flu or other illnesses among employees, as well as help determine what variables will cause someone to leave. [41] found that the variables that affect employee turnover include higher education, number of years of working for the previous employer, changes in salary, history of promotions, and so on.

A survey conducted by Accenture in 2019 revealed that more than half of employees (64\%) are afraid of losing their privacy. The use of Big Data analysis requires a company to be transparent and have the consent of the persons affected. Also, company ISs should be protected so that the loss of personal data or the violation of an employees' privacy does not occur [42]. 
Via Big Data analysis, a company can enhance its productivity and fill job vacancies appropriately. According to Lipkin [43], Big Data analysis related to HR that is transparently focused on how individual activities directly affect the company's performance can positively change the relationship between the employer and the employees [44]. For this reason, Hamilton and Sodeman [42] think that the application of Big Data analysis in the field of human resources can help strategically manage $\mathrm{HC}$ and bring higher individual performance as well as stability [45].

Since several studies came to the conclusion that Industry 4.0, besides technological advancement and business automation, will bring unemployment, it is necessary for company managers to focus their attention on the identification of new skills and abilities that will be needed in the future. The purpose of HCM lies mainly in the retention of capable employees in a company whose activity is reflected in its overall operations. Therefore, it is in a company's best interests to strive to protect current employees, adapt to more and more demanding conditions, and increase employees' qualifications.

Beyond the efforts to retain and train current employees, it will also be necessary to attract, retain and integrate new talents in companies. HR managers should therefore prepare themselves for a new definition of human resources, HC and hiring.

It will also be necessary for managers to focus on new ways of learning and development, so that new as well as current employees maintain their relevance and qualifications. One of the transitions within Industry 4.0 is artificial intelligence, leading to a change in the hiring of employees from the data management to the intelligence kind. It is predicted that within the next two years, a large number of HR teams will rely on machine learning and artificial intelligence in their HC activities [46].

\section{Acknowledgement}

This work was supported by project VEGA 1/0382/19 Building a sustainable relationship with stakeholders of enterprise through value creation using ICT.

\section{References}

1. R. Kumar, Human Resource Management: Strategic Analysis Text and Cases. New Delhi: IK International Publishing House (2011)

2. J. Porvazník, Celostná manažérska kompetentnost' - potreba, prístupy a metódy jej ohodnocovania [Holistic managerial competence - need, approaches and methods of its evaluation]. In Zborník vedeckých prác z vedeckého seminára. Bratislava: Ekonóm (2013)

3. L. Ližbetinová, M. Hitka, Selection of Most Suitable Candidates for the Talent Pool in a Furniture Manufacturing Company. Drvna Industrija. 67(4), 333-340 (2016)

4. E. E. Lawler, Make human capital a source of competitive advantage. Organizational Dynamics. 38 (1), 1-7 (2009)

5. P. Ghosh, What is Human Capital Management (HCM)? Definition, Process, Platforms (tools) with Examples [online]. Available at: https://www.hrtechnologist.com/articles/performance-management-hcm/what-is-human-capitalmanagement/ (2019)

6. MSG: MANAGEMENT STUDY GUIDE, Human Capital Management - Meaning and Important Concepts [online]. Available at: https://www.managementstudyguide.com/human-capital-management.htm (2019)

7. M. D’Angelo, Beyond Human Resources: 4 Ways to Improve Human Capital Management. [on-line]. Available at: https://www.businessnewsdaily.com/8145-human-capital-

management.html?fbclid=IwAR19BmAI3xhyeO8xWRB1ONJkOXgGrg6gD0v9hugzKHPaknTQAua1oWNN3DI (2019)

8. Personio, Human Capital Management [on-line]. Available at: https://www.personio.com/hr-lexicon/humancapital-management-hcm/ (2019)

9. M. Durišová, E. Tokarčíková, F. O. Virlanuta, Z. Chodasová, The corporate performance measurement and its importance for the pricing in a transport enterprise. Sustainability. 11(21), 1-17 (2019)

10. E. Malichová, M. Ďurišová, E. Tokarčíková, Models of application economic value added in automotive company. Transport Problems. 12(3), 93-102 (2017)

11. M. Nadanyiová, J. Majerová, J. Oláh, 2019. Financing of adverts and its impact on the brand value. Littera Scripta. 12(2), 1-12. (2019)

12. A. Kucharčíková, M. Mičiak, Human capital management in transport enterprises with the acceptance of sustainable development in the Slovak Republic. Sustainability. 10(7), 1-18 (2018) 
13. I. Kmecová, J. Stuchlý, L. Polanecký, M. Šuta, Analysing structure of employed and unemployed population of Czech Republic as part of human capital on labour market. Littera Scripta. 12(1), 1-21 (2019)

14. M. Hitka, S. Lorincová, L. Ližbetinová, J. Schmidtová, Motivation preferences of Hungarian and Slovak employees are significantly different. Periodica Polytechnica Social and Management Sciences. 25(2), 117-126 (2017)

15. L. Ližbetinová, M. Hitka, C. Li, Z. Caha, Motivation of employees of transport and logistics companies in the Czech Republic and in a Selected Region of the PRC. MATEC Web Conferences. 134(8) (2017)

16. K. Stachová, Z. Stacho, J. Blštáková, M. Hlatká, L. M. Kapustina, Motivation of Employees for Creativity as a Form of Support to Manage Innovation Processes in Transportation-Logistics Companies. Nase More. 65(4), 180-186 (2018)

17. Z. Stacho, K. Stachová, M. Hudáková, R. Stasiak-Betlejewska, Employee adaptation as key activity in human resource management upon implementing and maintaining desired organisational culture. Serbian Journal of Management. 12(2), 305-315 (2017)

18. B. Marr, What is Industry 4.0? Here's A Super Easy Explanation For Anyone. [online]. Available at: https://www.forbes.com/sites/bernardmarr/2018/09/02/what-is-industry-4-0-heres-a-super-easy-explanation-foranyone/\#7fa47df49788 (2020)

19. Lu, Y., Industry 4.0: A survey on technologies, applications and open research issues. Journal of Industrial Information Integration. 6, 1-10 (2017)

20. K. Kuba, F. Milichovský, Industry 4.0 and its impact on employees’ age. Littera Scripta. 12(1), 1-12 (2019)

21. Z. Kozubíková, The 4th industrial revolution: a challenge for the education system. In International conference on informatization of economic and management processes. 217-222 (2016)

22. O. Bayraktar, C. Atac, The Effects of Industry 4.0 on Human Resources Management. In: Y. Ertugrul, C. Hamza, Globalization, Institutions and Socio-Economic Performance. Berlin: Peter Lang GmbH. 337-360 (2018)

23. L. Bonekamp, M. Sure, 2015. Consequences of Industry 4.0 on Human Labour and Work Organisation. Journal of Business and Media Psychology. 6(1), 33-40 (2015)

24. J. E. Agolla, Human Capital in the Smart Manufacturing and Industry 4.0 Revolution In: A. Petrillo, R. Cioffi, F. De Felice, Digital Transformation in Smart Manufacturing (2018)

25. HCM, 4 Features of a Human Capital Management Solution [on-line]. Available at: https://www.paychex.com/articles/hcm/4-features-of-a-human-capital-management-solution (2015)

26. ATPJOURNAL. Papierové riadenie je brzdou firiem, ich rozvoju pomôže digitalizácia [Paper management is a brake on companies, their development will be helped by digitization]. [online]. Available at: https://www.atpjournal.sk/hlavna-stranka/slovenska/rubriky/podujatia/papierove-riadenie-jebrzdou-firiemichrozvoju-pomoze-digitalizacia.html?page_id=27071 (2018)

27. A. Bendová, Meniaci sa svet výroby volá po digitalizácii [The changing world of production is calling for digitization]. [online]. Available at: http://industry4.sk/magazin/industry-4-0/meniaci-sa-svet-vyroby-vola-podigitalizacii/ (2018)

28. M. Šikýř, V. Sekerin, A. Gorokhova, Managing Human Resources Using the Best Practice. Best Fit Approach. Journal of Applied Economic Sciences. 13(1), 113-122 (2018)

29. P. Daheb, The Digitization of Human Resources. [online]. Available at: https://michaelskenny.com/points-ofview/digitization-of-hr/ (2020)

30. L. Trnka, M. Gogola, Analysis of the tire contact area pressure on the road. Perner's Contacts. 14(2), 49-59 (2019)

31. R. Eller, P. Alford, A. Kallmünzer, M. Peters, Antecedents, consequences, and challenges of small and mediumsized enterprise digitalization. Journal of Business Research. 112, 119-127 (2020)

32. P. Lalwani, What Is HR Digital Transformation? Definition, Strategies, and Challenges. [online]. Available at: https://www.toolbox.com/hr/hr-innovation/articles/what-is-hr-digital-transformation-definition-strategies-andchallenges/ (2020)

33. L. Bartuška, J. Hanzl, L. Ližbetinová, Possibilities of Using the Data for Planning the Cycling Infrastructure. Procedia Engineering. 161, 282-289 (2016)

34. A. De Mauro, M. Greco, M. Grimaldi, P. Ritala, Human resources for Big Data professions: A systematic classification of job roles and required skill sets. Information Processing \& Management. 54(5), 807-817 (2018)

35. N. Shah, Z. Irani, A. M. Sharif, Big data in an HR context: Exploring organizational change readiness, employee attitudes and behaviors. Journal of Business Research. 70, 366-378 (2017) 
36. M. Hitka, S. Lorincová, L. Ližbetinová, G. P. Bartáková, M. Merková, Cluster Analysis Used as the Strategic Advantage of Human Resource Management in Small and Medium-sized Enterprises in the Wood-Processing Industry. BioResources. 12(4), 7884-7897 (2017)

37. Parsers, How and why HR uses Big Data: big data technologies in human resources management [online]. Available at: https://parsers.me/how-and-why-hr-uses-big-data-big-data-technologies-in-human-resources-management/ (2019)

38. insideBIGDATA, 6 Ways Companies Are Using Data Analytics to Reduce Expenses [online]. Available at: https://insidebigdata.com/2019/02/24/6-ways-companies-are-using-data-analytics-to-reduce-expenses/ (2019)

39. M. Zarembo, 6 Ways Big Data Will Change HR. [online]. Available at: https://www.aberdeen.com/hcmessentials/6-ways-big-data-will-change-hr/ (2020)

40. V. Kumar, The Role of Big Data in Human Resource Management. [online]. Available at: https://info.aiim.org/aiimblog/role-of-big-data-in-human-resource-management (2018)

41. S. Dil, Big Data Can Help Cut Employee Turnover Costs. [online]. Available at: https://www.predictiveanalyticsworld.com/machinelearningtimes/big-data-can-help-cut-employee-turnovercosts/6565/ (2020)

42. R. H. Hamilton, W. A. Sodeman, The questions we ask: Opportunities and challenges for using big data analytics to strategically manage human capital resources. Business Horizons. 63(1), 85-95 (2020)

43. J. Lipkin, Sieving through the data to find the person: HR's Imperative for Balancing Big Data with People

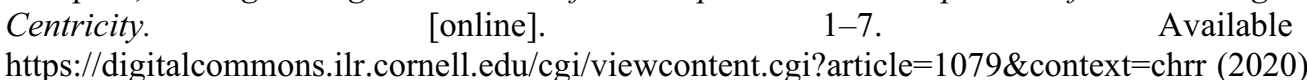

44. S. Lorincová, M. Hitka, P. Štarchoň, K. Stachová, Strategic Instrument for Sustainability of Human Resource Management in Small and Medium-Sized Enterprises Using Management Data. Sustainability. 10(10), 3687 (2018)

45. J. Blstakova, Z. Joniakova, Z. Skorkova, I. Nemethova, R. Bednar, Causes and Implications of the Applications of the Individualisation Principle in Human Resources Management. AD ALTA: Journal of Interdisciplinary Research. 9(2), 323-327 (2019)

46. S. Libu, Recruitment in the Era of Industry 4.0 [online]. Available at: https://www.highereducationdigest.com/recruitment-in-the-era-of-industry-4-0/ (2019) 